\title{
Correction to: Chapter 11: Speaking from the Ground: Transitional Gender Justice in Nepal
}

Punam Yadav

Correction to: Rethinking Transitional Gender Justice https://doi.org/10.1007/978-3-319-77890-7

This chapter was inadvertently published with an error. Correction was made to the order of the author's name in the references.

The updated online version of this chapter can be found at https://doi.org/10.1007/978-3-319-77890-7_11

P. Yadav $(\bowtie)$

Centre for Gender and Disaster, Institute for Risk and Disaster Reduction, University College London, London, UK

e-mail: p.yadav@ucl.ac.uk

R. Shackel, L. Fiske (eds.), Rethinking Transitional Gender Justice, Gender, Development and Social Change, https://doi.org/10.1007/978-3-319-77890-7_18 